\title{
Effect of fetal brainsparing on the early neonatal cerebral circulation
}

\author{
Sicco A Scherion, Hans Oosting, Joke H Kok, Hans A Zondervan
}

\begin{abstract}
The effect of antenatal brainsparing on subsequent neonatal cerebral blood flow velocity (CBFV) was studied in very preterm infants. CBFV was determined, using a pulsed Doppler technique, both in the fetal and neonatal period. Neonatally, blood pressure and transcutaneous carbon dioxide tension $\left(\mathrm{TcPCO}_{2}\right)$ was monitored simultaneously; daily cranial ultrasound examinations were performed.

In infants with evidence of brainsparing a higher mean value of CBFV and a different pattern of changes of CBFV during the first week of life was demonstrated compared with infants with normal fetal cerebral haemodynamics. No differences were found in blood pressure and $\mathrm{TcPCO}_{2}$. The incidence of intracranial haemorrhages and of ischaemic echodense lesions was also the same for both groups.

In a multivariate statistical model gestational age, antepartum brainsparing, and $\mathrm{TcPCO}_{2}$ all contributed significantly in explanation of variation in CBFV. It is speculated that a different setting of cerebral autoregulation related to differences in gestational age or to brainsparing might explain the difference in changes found in neonatal CBFV.

(Arch Dis Child 1994; 71: F11-F15)
\end{abstract}

Following the report of Bada et al in $1979^{1}$ considerable interest in the study of neonatal cerebral haemodynamics using Doppler ultrasound has arisen. The use of this technique in neonatology has been reported in a wide variety of pathological conditions including ductal patency, pneumothorax, and hydrocephalus. The association between intracranial haemorrhage $(\mathrm{ICH})^{2}$ or neonatal asphyxia ${ }^{3}$ and blood flow velocity waveforms has also been widely investigated. More recently, Wladimiroff et $a^{4}$ and Arduini et $a l^{5}$ showed the feasibility of the pulsed Doppler technique, in combination with real time ultrasound in examining the fetal cerebral circulation. The phenomenon of fetal blood flow redistribution occurring in severe intrauterine growth retardation, well known from animal studies, ${ }^{6}$ could also be demonstrated in human pregnancy. ${ }^{7}$ During normal pregnancy the lowest vascular resistance is at the level of the placenta. However, during severe fetal growth retardation the region with the lowest vascular resistance is no longer the placental vascular bed, but will be at the level of cerebral vessels. In severe fetal growth retardation this will result in a decrease of end diastolic velocities in the umbilical artery, while an increase in end diastolic velocities in cerebral vessels can be found. This centralisation of the fetal circulation is known as the 'brainsparing' effect. The ratio of umbilical pulsatility index (PI)/cerebral PI (U/C ratio) has been used as an index of the brainsparing effect. ${ }^{4}$ In fetal growth retardation a significant increase in U/C ratio was found. ${ }^{7}$ Consequences of antenatal brainsparing on cerebral haemodynamics in the preterm infant after birth are unknown. Therefore we studied the relation between antenatal haemodynamic adaptation as defined by a raised U/C ratio and cerebral haemodynamics in the neonatal period.

\section{Patients and methods}

A cohort of 117 pregnant women consecutively admitted to our department between February 1989 and December 1989 was studied. One pregnancy resulting in the birth of an infant with Down's syndrome was excluded. Two patients refused to take part in the study. In 11 cases intrauterine fetal death occurred. The data of 103 pregnancies resulting in the birth of 128 liveborn infants, with a gestational age at delivery between 25 and 33 weeks are reported. Reasons for hospital admission were imminent preterm labour $(n=83)$, severe growth retardation $(n=4)$, second/third trimester haemorrhage $(n=2)$, abruptio placentae $(n=2)$, and pregnancy induced hypertension $(n=12)$. There were 81 singletons, 19 twin pregnancies resulting in the birth of 38 infants, and nine infants from triplet pregnancies.

\section{FETAL BLOOD FLOW VELOCITY STUDIES}

Antenatally, flow velocity waveforms were recorded from the umbilical artery and the middle cerebral artery. Recordings of signals from the middle cerebral artery were made at the level of the bifurcation of the internal carotid artery into the anterior and middle cerebral artery. Vessels were identified by real time ultrasound with a $3.5 \mathrm{MHz}$ sector scanner (DRF400, Diasonics). Flow velocity waveforms were obtained with a $2 \mathrm{MHz}$ pulsed Doppler probe (SD50 VingMed) attached to the imaging probe at a fixed angle of insonation of 30 degrees. $^{8}$ Sample volume was $3 \mathrm{~mm}$ and the high pass filter was set at the lowest possible level of $100 \mathrm{~Hz}$. Back scattered Doppler signals were displayed visually as a sonogram and the audiosignals were stored on audiotape. Recordings were made directly after maternal 
admission and thereafter at weekly intervals. The last measurement before birth was used for analysis. By replaying the stored audiosignal, spectral analysis was performed off-line using fast Fourier transformation. Calculations were performed on the maximum frequency envelope of the Doppler shift, which was automatically recognised by the Vingmed SD 50. PI: $\left(\mathrm{V}_{\text {sys }}-\mathrm{V}_{\text {dias }}\right) / \mathrm{V}_{\text {mean }}{ }^{9}$ was calculated over at least five sequential cardiac cycles. Then the ratio of umbilical $\mathrm{PI} /$ cerebral $\mathrm{PI}$ (U/C ratio) was calculated.

We found in an earlier study that the one sided tolerance limit of the U/C ratio, calculated for normal pregnancies with a gestational age ranging from 25 to 33 weeks was $0 \cdot 72 .^{10}$ This limit delineates the lowest 95\% confidence interval of a $5 \%$ chance for normal pregnancies to have a $\mathrm{U} / \mathrm{C}$ ratio above this limit. A U/C ratio above the tolerance limit was considered to be indicative of the brainsparing effect. Infants were grouped according to the presence of signs of brainsparing.

NEONATAL CEREBRAL BLOOD FLOW VELOCITY (CBFV) STUDIES

In the immediate neonatal period, flow velocity waveforms from the middle cerebral artery were recorded in the transcranial plane. The same Doppler equipment was used. The Doppler transducer was placed on the temporal bone at $0.5-1 \mathrm{~cm}$ in front of the ear. ${ }^{11}$ The angle between the Doppler beam and the axis of the vessel is near zero and permits determination of absolute flow velocities in this artery. The initial depth setting was $2.0 \mathrm{~cm}$ and by ranging the depth, the localisation of the sample volume was adjusted to obtain the maximal signal. The maximum frequency shift and thus the highest possible velocities were obtained by listening to the audio signal and observing the sonogram in real time. The complete audio spectrum was used to calculate the time averaged mean velocity $\left(\mathrm{V}_{\text {mean }}\right) \cdot{ }^{12}$ By replaying the audiotapes $\mathrm{V}_{\text {mean }}$ was calculated off-line automatically by the integrated computer system (SD50 VingMed) over at least five sequential cardiac cycles. Doppler studies in the neonate were performed at $1,2,4,8,12,24,48,72,120$, and 168 hours after birth. Doppler studies were performed by one investigator (SAS). The results of the Doppler studies were not available to the attending clinicians.

OTHER MEASUREMENTS

Simultaneously with the neonatal Doppler recordings mean arterial blood pressure (MAP) (Dinamap $1846 \mathrm{SX}$ ) and transcutaneous carbon dioxide tension $\left(\mathrm{TcPCO}_{2}\right)$ (Hewlett Packard, type 78834A) were measured.

Neurosonography was performed at fixed intervals during the first week of life and stored on videotape. Neurosonographic findings were categorised by one observer (SAS) who was unaware of patient characteristics. The most severe ultrasound diagnosis at the end of the first week of life was used for classification. ICH was classified as proposed by Volpe. ${ }^{13}$ For
Table 1 Combined neurosonographic classification

\begin{tabular}{ll}
$\begin{array}{l}\text { Ultrasound } \\
\text { classification }\end{array}$ & Criteria \\
\hline Normal & $\begin{array}{l}\text { No intracranial haemorrhage or a subependymal } \\
\text { haemorrhage. Echodensities less bright than } \\
\text { the choroid plexus }\end{array}$ \\
Suspect & $\begin{array}{l}\text { Intraventricular haemorrhage }(<50 \% \text { of lumen } \\
\text { filled). Any echodensity brighter than the } \\
\text { choroid plexus, lasting less than three days }\end{array}$ \\
Abnormal & $\begin{array}{l}\text { Intraventricular haemorrhage }(>50 \% \text { of lumen } \\
\text { filled) and any intraparenchymal } \\
\text { haemorrhage. Any echodensity brighter than } \\
\text { the choroid plexus and lasting for more than } \\
\text { three days. }\end{array}$
\end{tabular}

the classification of ischaemic lesions known as echodensities the description of Pidcock et al was used. ${ }^{14}$ Any intraventricular haemorrhage or intraparenchymal haemorrhage was classified as a severe haemorrhage. Echodensities brighter than the choroid plexus and lasting for more than three days were considered severe forms of echodensities. The infants were subdivided according to evidence of severe ICH and/or severe echodensities on cranial ultrasound. For further analysis a classification based on the combination of haemorrhages as well as ischaemic lesions was used (table 1).

Infants were regarded as small for dates if their birth weight was below the 10th centile for gestational age, taking maternal parity and sex into account. ${ }^{15}$ All clinical decisions were made according to department standards. The study was approved by the ethics committee of the hospital.

\section{STATISTICS}

Mann-Whitney U test, Fisher's exact probability test, and analysis of variance for repeated measurements were used when appropriate, using the BMDP statistical program package. $\mathrm{CBFV}$ as the dependent variable was analysed using repeated measurements analysis. U/C ratio and gestational age were used as explaining variables; the time changing variables MAP and $\mathrm{TCPCO}_{2}$ were used as covariables. The within subject covariance matrix was specified as having the compound symmetry structure. The coefficient of determination $\left(R^{2}\right)$ was used to estimate the proportion of explained variance in neonatal CBFV. ${ }^{16}$ To select variables contributing significantly to the model a stepwise backward selection procedure based on the likelihood ratio test was done. This procedure means that first all variables are included in the model. Each variable not contributing significantly to the model were then successively excluded. Because data of the infants who died in the very early neonatal period could influence the result of the total group the data were analysed with and without these infants. A $p$ value of less than 0.05 was assumed to denote a significant difference.

\section{Results}

In 117 of the 128 infants enrolled in the study, signals from the middle cerebral artery were recorded antenatally $(91 \%)$. In the other 11 cases (singletons) we were unable to record the signals because of a short time lag between 
Table 2 U/C ratio and obstetrical outcome

\begin{tabular}{lll}
\hline & U/C ratio & \\
\cline { 2 - 3 } \cline { 2 - 3 } & $\begin{array}{l}\text { Normal } \\
(n=74)\end{array}$ & $\begin{array}{l}\text { Raised } \\
(n=43)\end{array}$ \\
\hline Range (median) gestational age (days) & $179-230(207)$ & $188-230(220)^{\star}$ \\
Range (median) birth weight $(\mathrm{g})$ & $705-2295(1330)$ & $605-1940(1125)^{\star \star}$ \\
Appropriate weight for dates $(\geqslant 10$ th centile) & 1 & 22 \\
Small for dates $(<10$ th centile) & 73 & 21 \\
\hline
\end{tabular}

${ }^{\star} \mathrm{p}<0.01 ;{ }^{\star \star} \mathrm{p}<0.001$

admission and delivery $(n=9)$ or because of the occipitoanterior position of the fetal head $(n=2)$. Gestational age at birth of the infants ranged between 25 and 33 weeks (median 30 weeks). Birth weight ranged between 605 and $2295 \mathrm{~g}$ (median $1245 \mathrm{~g}$ ).

The 117 infants were divided into two groups according to their antenatally determined U/C ratio. The group with a raised U/C ratio consisted of $43(37 \%)$ infants. The remaining $74(63 \%)$ infants had a normal U/C ratio (that is below the tolerance limit). Obstetrical outcome was different for the two groups (table 2). Five infants died within the first four days of birth because of immaturity $(n=3)$ or respiratory insufficiency $(n=2)$. Another five infants died later in the neonatal period. Causes of death were sepsis $(n=3)$ and multiorgan failure $(n=2)$.

The incidence of ICH and of ischaemic lesions was not different between the two U/C ratio groups (table 3 ). Using the combined classification of neurosonographic findings as given in table 1 the relations between the U/C ratio, being small for dates, and brain damage were further explored. These results are given in table 4.

TIME PATTERN OF $\mathrm{V}_{\text {mean }}$ IN RELATION TO U/C RATIO

The pattern of changes of $\mathrm{V}_{\text {mean }}$ in the middle cerebral artery during the first week of life for infants with a normal or with a raised U/C ratio is shown in the figure. For both groups a profound decrease in $\mathrm{V}_{\text {mean }}$ was seen after the

Table 3 Neurosonographic findings; figures are number (\%)

\begin{tabular}{lllll}
\hline & \multicolumn{4}{l}{ Neurosonography } \\
\cline { 2 - 5 } U/C ratio & IC & Severe & No & ICH \\
echodensities & $\begin{array}{l}\text { Severe } \\
\text { echodensities }\end{array}$ \\
\hline Normal & $62(84)$ & $12(16)$ & $61(83)$ & $13(17)$ \\
Raised & $39(91)$ & $4(9)$ & $39(91)$ & $4(9)$
\end{tabular}

In five infants a severe ICH was found in combination with a severe echodensity. For the classification of no $v$ severe ICH or echodensities see text.

Table 4 Relation between U/C ratio, being small for date, and brain damage

\begin{tabular}{lllll}
\hline \multirow{2}{*}{ U/C ratio } & Small & \multicolumn{3}{l}{ Cranial ultrasound } \\
\cline { 3 - 5 } & for dates & Normal & Suspect & Abnormal \\
\hline Normal & No $(\mathrm{n}=73)$ & 52 & 9 & 12 \\
\multirow{2}{*}{ Raised } & Yes $(\mathrm{n}=1)$ & 1 & $\overline{2}$ & $\overline{2}$ \\
& No $(\mathrm{n}=21)$ & 17 & 2 & -
\end{tabular}

For the classification of normal, suspect, or an abnormal cranial ultrasound see table 1 .

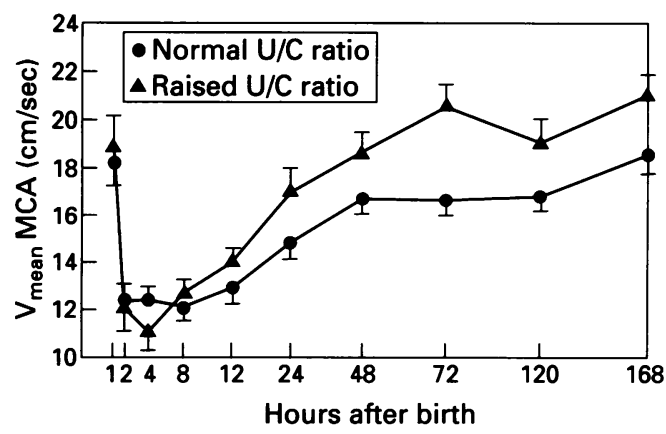

Time averaged mean (SEM) velocity $\left(V_{\text {mean }}\right)$ of the middle cerebral artery (MCA) during the first week of life for infants with a normal or raised U/C ratio.

first measurement directly after birth. Thereafter a gradual increase was found. Analysis of variance showed that infants with a raised $\mathrm{U} / \mathrm{C}$ ratio appeared to have, compared with infants with a normal U/C ratio, not only higher $\mathrm{V}_{\text {mean }}$ values during the first week of life $(p=0.017)$, but also a significantly different pattern of change of $V_{\text {mean }}$ in the middle cerebral artery during the first week of life $(p=0 \cdot 005)$. Even after exclusion of infants who died in the very early neonatal period $(n=5)$ the relation between $U / C$ ratio and $\mathrm{V}_{\text {mean }}$ (both mean values and pattern of change) remained $(p<0.01)$. After excluding infants with a severe $\mathrm{ICH}$ (intraventricular and/or intraparenchymal haemorrhage) $(n=16)$ the difference in neonatal CBFV (mean and change of $V_{\text {mean }}$ ) between the two groups remained significant $(p<0.02)$. Exclusion of infants with severe echodensities on cranial ultrasound did not influence the results of the analysis.

TIME PATTERN OF TCPCO ${ }_{2}$ AND MEAN ARTERIAL BLOOD PRESSURE

Directly after birth high $\mathrm{TcPCO}_{2}$ values were found. Infants with a normal U/C ratio had a mean (SD) $\mathrm{TcPCO}_{2}$ of $7 \cdot 2(3.68) \mathrm{kPa}(54 \cdot 1$ $(27 \cdot 7) \mathrm{mm} \mathrm{Hg}$ ) as measured one hour after birth, whereas infants with a raised U/C ratio had a mean $\mathrm{TcPCO}_{2}$ value of $5.89(1.33) \mathrm{kPa}$ (44.2 (9.9) $\mathrm{mm} \mathrm{Hg}$ ). For both groups a gradual decrease took place in the 24 hours after birth. After 24 hours an increase was seen until day 7 . $\mathrm{TcPCO}_{2}$ raised to $6 \cdot 21(1 \cdot 20) \mathrm{kPa}$ $(46.6(9.0) \mathrm{mm} \mathrm{Hg})$ and $5.60(0.95) \mathrm{kPa}(42.0$ $(7 \cdot 2) \mathrm{mm} \mathrm{Hg}$ ) in the normal and raised U/C ratio group, respectively.

MAP increased gradually both in infants with a normal as well as in infants with a raised U/C ratio. At one hour after birth the MAP for infants with a normal U/C ratio was $37 \cdot 8(6 \cdot 7)$ $\mathrm{mm} \mathrm{Hg}$; for infants with a raised U/C ratio the MAP was $37 \cdot 2(5 \cdot 4) \mathrm{mm} \mathrm{Hg}$. At seven days postpartum MAP reached to $48 \cdot 1(7 \cdot 7) \mathrm{mm}$ $\mathrm{Hg}$ and $47.5(8 \cdot 2) \mathrm{mm} \mathrm{Hg}$, respectively.

Statistical analysis did not show a significant difference in mean level of $\mathrm{TcPCO}_{2}$ and MAP for infants with a normal U/C ratio compared with infants with a raised U/C ratio. We also could not show any difference in the average pattern of change in $\mathrm{TcPCO}_{2}$ and $\mathrm{MAP}$ between the two U/C ratio groups. 
Table 5 Relation between neonatal CBFV and some variables

\begin{tabular}{llrl}
\hline Variable $(X)$ & $\mathrm{R}$ & $p$ Value & Regression line \\
\hline TcPCO $_{2}$ & 0.19 & 0.047 & $\mathrm{y}=11.9+0.07 \times \mathrm{X}$ \\
Gestational age & 0.40 & $<0.001$ & $\mathrm{y}=14 \cdot 8+0 \cdot 10 \times \mathrm{X}$ \\
U/C ratio & 0.28 & 0.002 & $\mathrm{y}=10 \cdot 6+1 \cdot 10 \times \mathrm{X}$ \\
\hline
\end{tabular}

ANALYSIS OF VARIANCE WITH REPEATED MEASUREMENTS

After the backward selection procedure the variables $\mathrm{TcPCO}_{2}$ and either gestational age or $\mathrm{U} / \mathrm{C}$ ratio were significantly associated with the level and time pattern of neonatal CBFV. Because gestational age and U/C ratio are highly correlated it is not possible to assess their independent effects on CBFV properly. The multivariate model which included the significantly correlating variables $\mathrm{TcPCO}_{2}$ and either gestational age or U/C ratio could explain $30 \%$ of the variation of $\mathrm{CBFV}$ in the neonatal period. When $\mathrm{TcPCO}_{2}$ was included in the model, analysis of variance for repeated measurements did not reveal any independent effect of MAP on neonatal CBFV changes.

The effect of $\mathrm{TcPCO}_{2}$, gestational age, or $\mathrm{U} / \mathrm{C}$ ratio on the level of CBFV is shown in table 5. The correlation coefficient $(R)$ between the individual mean of these variables and the individual mean CBFV quantifies these effects; $p$ values and the regression lines are shown.

\section{Discussion}

Brainsparing is defined as a circulatory adaptation of the fetus resulting in a preferential perfusion of the central nervous system. A raised $U / C$ ratio is a sensitive indicator of the brainsparing effect and it is indicative of fetal growth retardation. ${ }^{17}$ In our population only one infant with a normal U/C ratio appeared to be small for dates (table 2). In the group with a high U/C ratio $50 \%$ of the infants were above the 10th centile of the growth curve. As a flattening of intrauterine growth might still be compatible with a birth weight above the 10th centile, infants in the high U/C ratio group classified as normally grown, according to the classical definition, might still have been growth retarded.

Using the combined classification the incidence of abnormal ultrasound findings was higher in the infants without fetal brainsparing compared with infants with a normal U/C ratio (table 4). This finding was contrary to our expectation as we hypothesised that antenatal brainsparing might be associated with an increase in fetal and neonatal brain damage. Also the incidence of suspect ultrasound findings was not higher for infants with signs of brainsparing, compared with infants without. Interestingly, the incidence of suspect findings on cranial ultrasound were equally distributed among small for date infants and normally grown infants, although both groups exhibited antenatal signs of brainsparing.

Flow velocity data of the middle cerebral artery are important, as this vessel contributes to about $80 \%$ of fetal and neonatal hemispheric blood flow. ${ }^{18}$ Severe fetal growth retardation is clinically suspected especially at a more advanced gestational age. At early gestational age (for example, 25-26 weeks) pregnant women are seldom referred because of growth retardation. This makes it understandable that high U/C ratios were found especially at 30-33 weeks of pregnancy. It also explains the finding that high U/C ratios were so closely correlated with gestational age, making the assessment of the individual contribution of these variables on CBFV changes impossible.

Trend analysis of absolute changes of $\mathrm{V}_{\text {mean }}$ of the middle cerebral artery contains information on actual changes of cerebral blood flow. ${ }^{19} 20$ The profound decrease in $\mathrm{V}_{\text {mean }}$ immediately after birth is in agreement with other reports. ${ }^{21} 22$ Animal studies showed the fetal cerebral blood flow rate to be twice as high compared with adult animals. The rapid decrease in $V_{\text {mean }}$ is most probably a reflection of the transition from fetal to neonatal cerebral blood flow. This occurs within the first hours after birth. ${ }^{23}$ Absent end diastolic velocities, which are in our experience common on the first day, result in low $\mathrm{V}_{\text {mean }}$ values on the first day. After the initial decrease in CBFV there is a gradual increase. Gray et al have argued that the initial decrease cannot be explained by ductal patency alone. ${ }^{24}$ On the second day after birth $50 \%$ of preterm infants still have a patent ductus arteriosus. ${ }^{25}$ The fact that minor changes were seen in CBFV after day 2, suggests that the impressive changes on day 1 are not related to closure of the ductus arteriosus. The gradual increase in CBFV found after the first eight hours of life is shown in many other studies. ${ }^{21} 2226$

Carbon dioxide tension ${ }^{27}$ and also blood pressure $^{12}$ were found to be important regulators of cerebral blood flow especially in the distressed newborn. Therefore, changes in CBFV might be related to changes in blood gases and/or changes in blood pressure. High CBFV immediately postpartum reflects the relatively hypercarbic state during fetal life and delivery. The decrease in CBFV in the first hours after birth may be explained by the sudden fall in carbon dioxide tension due to the initiation of respiration. $\mathrm{TcPCO}_{2}$ values in our study are high immediately after birth and decrease significantly in the first 24 hours after birth. Although statistically the effect of $\mathrm{TcPCO}_{2}$ may be small, changes of $\mathrm{TcPCO}_{2}$ are profound especially on day 1 , and this will effect especially the early changes in CBFV. Because of the profound changes in $\mathrm{TcPCO}_{2}$, the effects of gestational age or of $U / C$ ratio on CBFV were less during the early period of haemodynamic transition. They were shown to have their effect especially at the end of the investigative period. Vasoactivity of major cranial vessels causing vasoconstriction of vessels that were dilated at birth was shown by Drayton and Skidmore. ${ }^{28}$ Carbon dioxide is the most important regulator of $\mathrm{CBFV}^{29}$ and it explained in animal experiments $55 \%-90 \%$ of the reduction of CBFV at birth. ${ }^{23}$ The relatively high $\mathrm{CBFV}$ in utero and directly after 
birth might also be a reflection of a low fetal oxygen tension; the decrease in CBFV being the result of the increase in neonatal arterial oxygen tension. We did not show a significant influence of changes in $\mathrm{TcPO}_{2}$ on changes in neonatal CBFV. From our data it seems unlikely that changes in CBFV occurred due to an increase of MAP. This does not exclude, however, that changes in MAP may have affected CBFV in some infants. This may particularly be the case at high $\mathrm{TcPCO}_{2}$ values resulting in a disturbed cerebral flow autoregulation.

As infants with a raised or normal U/C ratio did not differ significantly in their patterns of change in $\mathrm{TcPCO}_{2}$ and $\mathrm{MAP}$, we could not attribute the difference found between the two groups in neonatal pattern of CBFV to these variables. As the two groups had the same prevalence of both severe intracranial haemorrhages and of severe echodensities, a vasoconstrictive effect due to ICH or because of ischaemic lesions on CBFV is also unlikely. Because the analysis yielded the same results after exclusion of the infants with an abnormal cranial ultrasound, the observed differences in CBFV cannot be attributed to intracranial pathology.

The actual mechanism by which the brainsparing effect during fetal life exerts its influence on neonatal CBFV cannot be determined from our data. In the model either gestational age or the U/C ratio were significantly associated with changes in CBFV. The high CBFV for infants with a raised U/C ratio could be a continuation of the fetal situation where a growth retarded infant (as a result of chronic hypercarbia or chronic hypoxia) has a vasodilated cerebral circulation, resulting in a higher CBFV. ${ }^{30}$ Our findings are compatible with the findings of Yoshida et al that infants small for gestational age have a higher CBFV during systole. Intrauterine stress might, in analogy with the acceleration of lung maturation, induce a physiological alteration, leading to a different setting of the autoregulation of the cerebral circulation. A higher gestational age could have a maturational effect on cerebral autoregulation. This could also explain the association between gestational age and CBFV.

In conclusion: the level and time changes in CBFV were significantly related to $\mathrm{TcPCO}_{2}$, whereas gestational age or $\mathrm{U} / \mathrm{C}$ ratio both had a significant influence. No independent effect of changes of MAP on neonatal CBFV changes could be demonstrated when $\mathrm{TcPCO}_{2}$, gestational age, and $\mathrm{U} / \mathrm{C}$ ratio were included in the model.

1 Bada HS, Hajjar W, Chua C, Sumner DS. Non-invasive diagnosis of neonatal asphyxia and intraventricular hemorrhage by Doppler ultrasound. $₹$ Pediatr 1979; 95: 775-9.

2 Perlman JM, Volpe JJ. Cerebral blood flow velocity in relation to intraventricular hemorrhage in the preterm newborn infant. F Pediatr 1982; 100: 956-9.
3 Archer LNJ, Levene MI, Evans DH. Cerebral artery Doppler ultrasonography for prediction of outcome after perinatal asphyxia. Lancet 1986; ii: 1116-7.

4 Wladimiroff JW, Tonge HM, Stewart PA. Doppler ultrasound assessment of cerebral blood flow in the human fetus. Br $\mathcal{F}$ Obstet Gynaecol 1986; 93: 471-5.

5 Arduini D, Rizzo G, Romanini C, Mancuso S. Fetal blood flow velocity waveforms as prediction of growth retardation. Obstet Gynecol 1987; 70: 7-10.

6 Cohn EH, Sacks EJ, Heymann MA, Rudolph AM Cardiovascular responses to hypoxemia and acidemia in fetal lambs. Am f Obstet Gynecol 1974; 120: 817-24.

7 Scherjon SA, Smolders-DeHaas H, Kok JH, Zondervan HA. The 'brain-sparing effect'. Antenatal cerebral Doppler findings in relation to neurological outcome in very preterm infants. Am f Obstet Gynecol 1993; 169: 169-75.

8 Eik-Nes A, Marsal K, Brubakk AO, Kristoffersson K, Ulstein M. Ultrasonic measurement of human fetal blood flow. $\mathcal{F}$ Biomed Eng 1984; 4: 28-36.

9 Gosling RG, King DH. Continuous wave ultrasound as an alternative and complement to X-rays in vascular examination. In: Reneman RS, ed. Cardiovascular application of ultrasound. Amsterdam: North Holland, 1974: 266-85.

10 Scherjon SA, Kok JH, Oosting H, Wolf H, Zondervan HA Fetal and neonatal cerebral circulation: a pulsed Doppler study. F Perinat Med 1992; 20: 79-82.

11 Raju TNK, Zikos E. Regional cerebral blood velocity in infants. A real-time transcranial and fontanellar pulsed infants. A real-time transcranial and fontanellar pul

12 Evans DH, Schlindwein FS, Levene MI. The relationship between time averaged intensity weighted mean velocity between time averaged intensity weighted mean velocity and time averaged maximum velocity in neonat.

13 Volpe JJ. Intraventricular hemorrhage and brain injury in the premature infant. Clin Perinatol 1989; 16: 361-411.

14 Pidcock FS, Graziani LJ, Stanley C, Mitchell DG, Merton D. Neurosonographic features of periventricular echodensities associated with cerebral palsy in preterm infants. f Pediatr 1990; 116: 417-22.

15 Kloosterman GJ. On intrauterine growth. The significance of prenatal care. Int $\mathcal{F}$ Gynaecol Obstet 1970; 8: 895-912.

16 Nagelkerke NJD. A note on a general definition of the coefficient of determination. Biometrika 1991; 78: 691-2.

17 Wladimiroff JW, VanDenWijngaard JAGW, Degani S. Cerebral and umbilical arterial blood flow velocity waveforms in normal and growth retarded pregnancies. Obste Gynecol 1987; 69: 705-9.

18 Kurmanavichius J, Karrer G, Hebisch G, Huch R, Huch A Fetal and preterm newborn cerebral blood flow velocity. Early Hum Dev 1991; 26: 1 i 3-20.

19 Hansen NB, Stonestreet BS, Rosenkrantz TS, Oh W. Validity of Doppler measurements of anterior cerebral artery blood flow velocity: correlation with brain blood artery blood flow velocity: correlation with

20 Lundell BPW, Kennedy KA, Lindstrom DP, Sundell H. Stahlman MT. Intracranial Doppler flow velocimetry compared with extracranial carotid blood flow measurements. Acta Paediatr Scand 1986; 329 (suppl): 127-33

21 Archer LNJ, Evans DH, Levene MI. Doppler ultrasound examination of the anterior cerebral arteries of normal newborn infants: the effects of postnatal age. Early Hum Dev 1985; 10: 225-60.

22 Winberg P, Sonesson SE, Lundell BPW. Postnatal changes in intracranial arterial blood flow velocities in preterm infants. Acta Paediatr Scand 1990; 79: 1150-5.

23 Barker JH. Fetal and neonatal cerebral blood flow. $A m \mathcal{F}$ Physiol 1966; 210: 897-903.

24 Gray PH, Griffin EA, Drumm JE, Fitzgerald DE, Duingam NM. Continous wave Doppler ultrasound in evaluation of cerebral blood flow in neonates. Arch Dis Child 1983; 58 677-81.

25 Gentile R, Stevenson G, Dooley T, Franklin D, Kawabori I, Pearlman A. Pulsed Doppler echocardiographic determination of time of ductal closure in normal newborn infants. $\mathcal{F}$ Pediatr 1981; 98: 443-8.

26 Calvert SA, Ohlsson A, Hosking MC, Erskine L, Fong K, Shennan AT. Serial measurement of cerebral blood flow velocity in preterm infants during the first 72 hours of life. velocity in preterm infants during the
Acta Paediatr Scand 1988; 77: 625-31.

27 Leahy FAN, Cates D, MacCallum M, Rigatto H. Effect of $\mathrm{CO}_{2}$ and $100 \% \mathrm{O}_{2}$ on cerebral blood flow in preterm infants. Fournal of Applied Physiology: Respiratory, Environmental and Exercise Physiology 1980; 48: 468-74

28 Drayton MR, Skidmore R. Vasoactivity of the major intracranial arteries in newborn infants. Arch Dis Child 1987; 62: $236-40$.

29 Rosenkrantz TS, Diana D, Munson J. Regulation of cerebral blood flow velocity in nonasphyxiated, very low birthweight infants with hyaline membrane disease. f Perinatol 1988; 8: 303-8

30 VanBel $F$, VanDeBor $M$, Stijnen $T$, Ruys JH. Decreased cerebrovascular resistance in small for gestational age infants. Eur f Obstet Gynecol Reprod Biol 1986; 23: 137-44.

31 Yoshida H, Yasuhara A, Kobayashi Y. Transcranial Doppler sonographic studies of cerebral blood flow velocities in neonates. Pediatr Neurol 1991; 7: 105-10. 